\title{
Prototipe Perangkat untuk Pemantauan dan Pengendalian Berbasis Web Diiintegrasikan ke Smarthome System
}

\author{
Achmad Faris Nasyarudin ${ }^{1}$, Ritzkal $^{2}$, Arief Goeritno ${ }^{* 3}$ \\ ${ }^{1}$ Laboratorium Net-Centric Computing, Universitas Ibn Khaldun Bogor, Indonesia \\ ${ }^{2,3}$ Prodi Teknik Elektro, Universitas Ibn Khaldun Bogor, Indonesia \\ e-mail: ${ }^{1}$ achmadfaris@gmail.com, ${ }^{2}$ ritzkal@ ft.uika-bogor.ac.id, *33arief.goeritno@uika- \\ bogor.ac.id
}

\begin{abstract}
Abstrak
Telah dilakukan rancang bangun sebuah prototipe perangkat untuk sistem pengukuran level ketinggian air dalam tangki dan pengendalian sejumlah analogi lampu taman dan prototipe tersebut dapat diintegrasikan ke sistem smarthome. Tiga pokok bahasan pada makalah ini, meliputi pembuatan, pemrograman, dan pengukuran kinerja pototipe perangkat. Keterbentukan subsistem dilakukan melalui pengawatan terintegrasi antar peranti elektronika, agar diperoleh proses dan kondisi handshacking secara perangkat keras (hardware). Pemrograman subsistem dilakukan melalui pembuatan algoritma dan penyusunan sintaks, agar diperoleh handshacking secara perangkat lunak (software). Kinerja subsistem terukur ketika diintegrasikan ke smarthome system, agar diperoleh proses handshacking secara perangkat keras dan lunak. Kinerja prototipe perangkat saat pemantauan berupa informasi tentang ketinggian permukaan air pada tangki air dengan 3 (tiga) kondisi, yaitu kriteria "kosong", "sedang", dan "penuh", sedangkan pengendalian berupa informasi tentang operasi ON/OFF terhadap LED sebagai analogi lampu taman, dilakukan untuk 3 (tiga) posisi, yaitu posisi \#1, \#2, dan \#3. Prototipe subsistem terpabrikasi dapat diintegrasikan ke smarthome system ketika dilakukan uji validasi.
\end{abstract}

Kata kunci-prototipe perangkat terpabrikasi, peranti elektronika, pemantauan dan pengendalian fenomena fisiis berbasis web, smarthome system, smartphone berbasis Android

\section{Abstract}

The design and construction of a device prototype for a water level measurement system in a tank and controlling a number of garden light analogies has been carried-out and the prototype can be integrated into smarthome system. Three topics are discussed in this paper, including the manufacture, programming, and performance measurement of device prototypes. The formation of prototype of the device is done through wiring integration between electronic devices, in order to obtain the hardware handshacking. Programming the prototype of device is done through the creation of algorithms and preparation of syntax, in order to obtain the software handshacking. The performance of the prototype of device is measured when integrated into the Smarthome system, in order to obtain the hardware and software handshacking. The performance of prototype of the device when monitoring in the form of information about the water level in the water tank with 3 (three) conditions, namely the criteria of "empty", "medium", and "full", while the control in the form of information about the operation of ON/OFF of the LED as an analogy to the lamp garden are done for 3 (three) positions, namely position \#1, \#2, and \#3. The manufactured subsystem prototype can be integrated into the smarthome system when a validation test is performed. Prototype of the device for monitoring and control based-on web that can be integrated into the smarthome system.

Keywords — prototype of the fabricated devices, electronic devices, monitoring and driving for the physical phenomena web-based, smarthome systems, smartphone Androidbased. 


\section{PENDAHULUAN}

Perangkat elektronika berbasis mikrokontroler berbantuan sensor dan aplikasi Blynk [1] terhubung ke sistem Internet [2,3] untuk pendeteksian atau pengukuran level ketinggian air saat penuh atau berkurang, melalui pemberian perintah ke bagian [1-3]. Sistem otomatisasi dipasang sebagai bentuk pengembangan dari cara pemantauan berbasis operasi manual ke sistem berbasis perangkat elektronika untuk pengoperasian pompa listrik, sehingga kondisi kekosongan air pada tangki dapat diantisipasi. Pompa air berfungsi untuk penyedotan air dan proses pengisian air ke tangki (tandon) air secara otomatis berbantuan water level control [4], atau saklar listrik otomatis [5], maupun sensor jarak (distance sensor) jenis ultrasonik yang terintegrasi dengan mikrokontroler dan aplikasi Blynk [1-3]. Pemantauan dan pengendalian air minum dalam tangki dilakukan melalui informasi laporan status dan pengiriman purchase order secara otomatis kepada pemasok (supplier) air minum melalui electronic mail (email), sedangkan pendeteksian atau pengukuran level ketinggian air saat penuh atau berkurang melalui pemberian perintah ke bagian kontroler melalui pengoperasian smartphone berbasis Android [6], termasuk pemilihan smartphone pada umumnya [7].

Integrasi sejumlah peranti elektronika yang meliputi mikrokontroler keluarga AVR [8,9] maupun modul mikrokontroler Arduino [10], berbagai sensor (seperti distance sensor, temperature sensor, voice recognition sensor) [8], dan implementasi sebuah smartphone [6] berbantuan aplikasi, telah digunakan untuk sejumlah keperluan [8]. Mikrokontroler termanfaatkan pada sistem pemantauan [11], berupa modul Arduino MEGA2560 R3 dilengkapi sensor jarak dari jenis ultrasonik tipe HY-SRF05 [11] dengan pemrograman berbasis Arduino Integrated Development Environment (IDE) [12] yang berpedoman kepada bahasa pemrograman $\mathrm{C} / \mathrm{C}++$. Manfaat sistem pemantauan tersebut berupa (a) informasi ketersediaan air dalam tangki berupa laporan tentang status pengurangan dan penambahan air dan (b) pengiriman purchase order secara otomatis melalui electronic mail (email) kepada pemasok (supplier) air minum [11]. Sejumlah prototipe sebagai subsistem penyusun sistem smarthome yang terhubung ke jaringan telepon dan Internet, dapat digunakan untuk pengendalian pompa air, pemantauan ketinggian permukaan air pada tangki penampungan air, pengoperasian peralatan penerangan di dalam atau luar rumah, pengawasan seluruh aktivitas yang terjadi di rumah, atau bentuk kemudahan lain [13].

Keberadaan teknologi elektronika terbaru yang dinamakan smarthome (rumah pintar), dapat digunakan untuk pengontrolan peralatan elektronika hanya dengan satu pengontrol pusat, ataupun dapat dilakukan pengoontrolannya ketika tidak sedang berada di rumah [13]. Sistem smarthome merupakan sebuah sistem berbantuan komputer untuk pemberian segala kenyamanan, keselamatan, keamanan, dan penghematan energi yang berlangsung secara otomatis dan terprogram melalui komputer atau pengontrol mikro [14]. Keberadaan semua peralatan elektronika dapat dikendalikan secara otomatis dari jarak tertentu, termasuk di dalamnya sistem pengkondisian udara (air conditioning) dalam ruangan, pesawat televisi, home theatre, microwave, dan lampu [13]. Peruntukan sistem smarthome pada gedung atau rumah tinggal, dapat digunakan untuk pengendalian hampir semua perlengkapan dan peralatan pada rumah tinggal, mulai dari pengaturan tata lampu hingga ke berbagai peralatan rumah tangga melalui perintah berupa suara, sinar inframerah, atau kendali jarak-jauh (remote) [14]. Perencanaan dengan implementasi teknologi smarthome harus dimulai dengan pengaturan kabel-kabel elektronika pada tahap pembangunan rumah. Sebelum rumah mulai pembangunan, penentuan terhadap peralatan elektronika harus direncanakan dan dipertimbangkan [13].

Berpedoman kepada sejumlah hasil penelitian dan informasi tersebut, maka dilakukan upaya dalam pemanfaatan sejumlah sensor untuk pendeteksian atau pengukuran level ketinggian air dalam tangki (tandon) air dalam sebuah subsistem yang dapat diintegrasikan ke sistem smarthome. Pemanfaatan modul NodeMCU yang berfungsi sebagai mikrokontroler (pengontrol mikro) sekaligus sebagai interface untuk sistem berbasis web sebagai penghubung antara sistem

IJEIS Vol. 10, No. 2, October 2020 : $167-178$ 
smarthome dan perangkat pemantauan dan pengendalian berupa smartphone [3]. Rancang bangun sebuah prototipe perangkat berbasis web yang digunakan untuk pemantauan dan pengendalian dan dapat diintegrasikan ke smarthome system [13,14]. Prototipe perangkat difungsikan untuk pemantauan dan pengoperasian motor listrik arus searah penggerak pompa mikro untuk pemompaan air ke dalam analogi tangki air, berbantuan sensor ultrasonik tipe HYSRF05, dan pengoperasian sejumlah lampu taman yang dianalogikan dengan Light Emitting Diode (LED). Pengoperasian prototipe melalui smartphone berbasis Android berbantuan mikrokontroler NodeMCU ESP8266 dan sensor ultrasonik HY-SRF05 [2,3] dengan dukungan sejumlah aplikasi yang didasarkan kepada PHP: HyperTex Proprocessor (PHP), Sublime Text versi 3, XAMPP versi 3.2.4, dengan Transmission Control Protocol/Internet Protocol (TCP/IP). Diagram blok pembuatan prototipe pemantauan dan pengendalian berbasis web terintegrasikan ke smarthome system, seperti ditunjukkan pada Gambar 1.

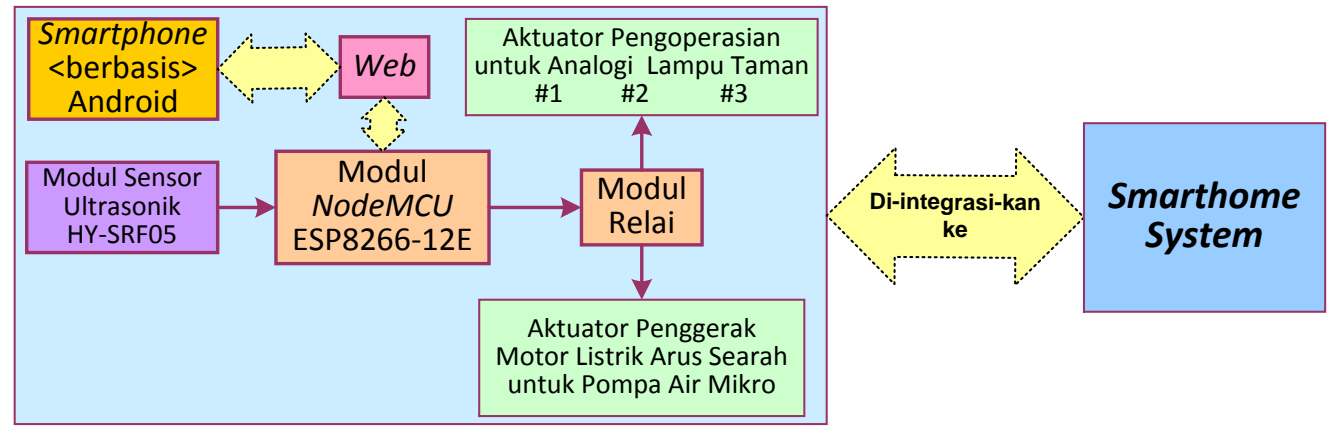

Gambar 1. Diagram blok pembuatan prototipe pemantauan dan pengendalian berbasis web terintegrasin ke smarthome system

Berpedomaan kepada Gambar 1, ditetapkan sasaran penelitian yang meliputi (1) merancang bangun prototipe sistem smarthome berbasis web dan berbantuan smartphone dan NodeMCU untuk pemantauan ketinggian permukaan air di dalam tangki dan pengendalian sejumlah $L E D$ sebagai analogi lampu-lampu taman; (2) membuat aplikasi berbasis Arduino IDE untuk mikrokontroler NodeMCU; dan (3) mengukur kinerja prototipe sistem dan implementasi pemanfaatan jaringan. Hasil pengukuran kinerja prototipe perangkat melalui proses handshaking secara hardware dan software digunakan sebagai pedoman untuk pembuatan prototipe subsistem yang dapat diintegrasikan ke sistem smarthome untuk pengendalian pompa listrik guna pengisian air ke dalam tangki dan pengoperasian lampu-lampu taman berbasis web dan terkendali melalui smartphone berbasis Android.

\section{METODE PENELITIAN}

Sejumlah bahan dan alat dibutuhkan pada penelitian ini sebagai dukungan terhadap proses pada metode penelitian, agar diperoleh sasaran penelitian melalui pembatasan masalah. Bahan penelitian ini berupa sejumlah modul untuk ketercapaian sebuah prototipe perangkat untuk sistem pemantauan dan pengendalian yang dapat diintegrasikan ke smarthome system. Kebutuhan perangkat lunak (software) penelitian, meliputi Arduino IDE, Windows 10, 64 bit Pro, HyperTex Proprocessor (PHP), Sublime Text versi 3, dan XAMPP. Diagram alir metode penelitian, seperti ditunjukkan pada Gambar 2. 


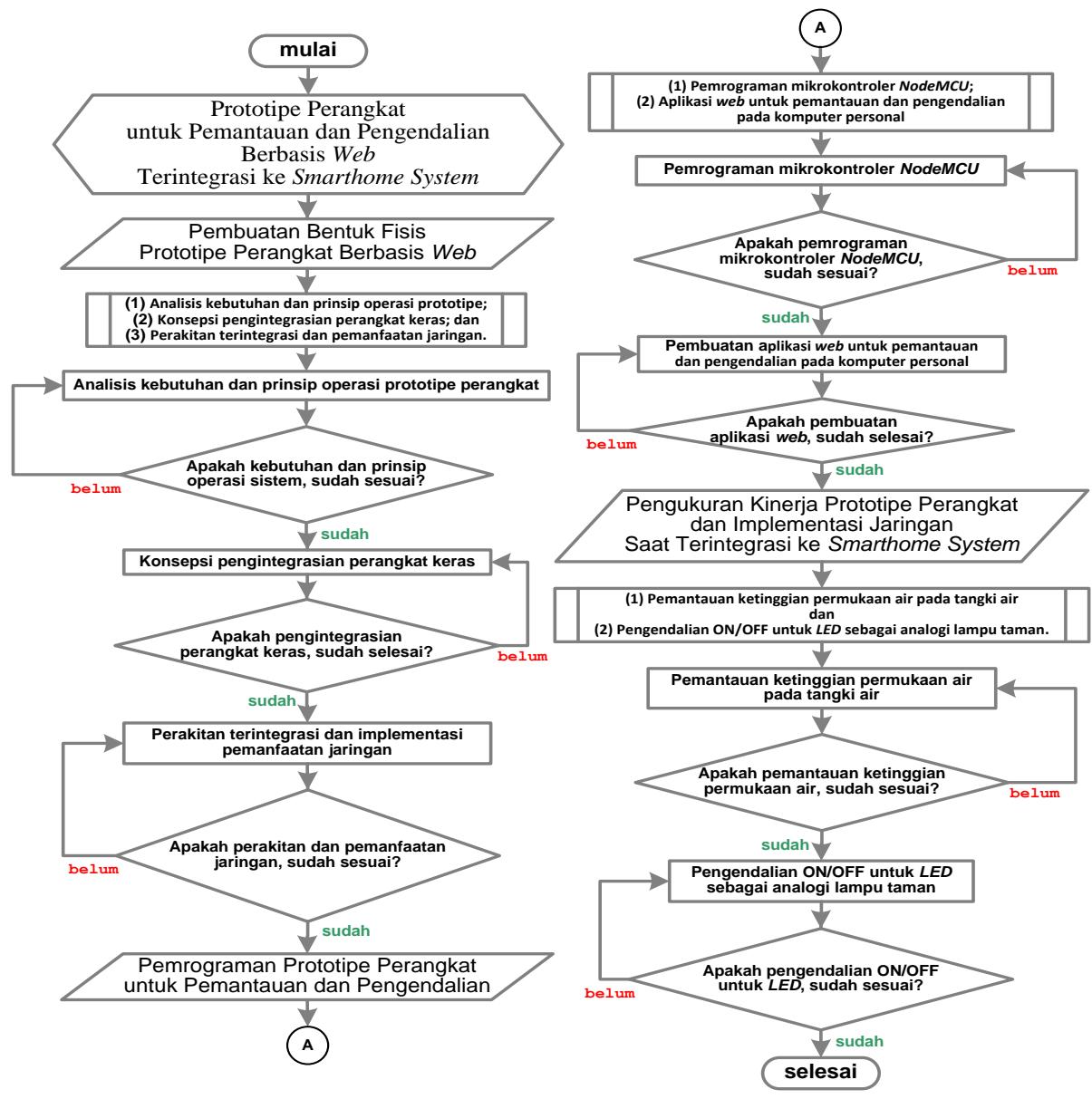

Gambar 2 Diagram alir metode penelitian

Berdasarkan Gambar 2 dapat dijelaskan, bahwa metode penelitian berisi langkah-langkah pelaksanaan untuk pencapaian sasaran penelitian.

\subsection{Pembuatan Bentuk Fisis Prototipe Perangkat Berbasis Web}

Proses pembuatan bentuk fisis prototipe sistem smarthome dilakukan melalui (i) analisis kebutuhan perangkat keras dan prinsip operasi sistem, (ii) konsepsi terintegrasi perangkat keras, dan (iii) perakitan terintegrasi dan implementasi pemanfaatan jaringan.

\subsection{Implementasi Pemrograman Prototipe Perangkat}

Pemrograman sistem smarthome, dimulai dari tahapan pemrograman untuk mikrokontroler berbasis bahasa Arduino IDE, melalui penentuan algoritma dan penulisan sintaks yang dilanjutkan dengan proses compiling dan uploading terhadap source code dari komputer personal (personal computer, PC) ke dalam mikrokontroler NodeMCU. Aplikasi web untuk pemantauan dan pengendalian pada komputer personal. Web untuk pemantauan dan pengendalian (web monitoring) digunakan pada komputer personal untuk pembuatan aplikasi sebagai sistem pemantauan dan pengendalian.

\subsection{Pengukuran Kinerja Prototipe Perangkat dan Implementasi Jaringan Saat Terintegrasi ke Smarthome System}

Pengukuran kinerja prototipe perangkat dan implementasi jaringan saat terintegrasi ke smarthome system, meliputi pemantauan ketinggian permukaan air pada tangki air yang dikelompokkan kepada 3 (tiga) kondisi, yaitu kriteria "kosong", "sedang", dan "penuh" dan

IJEIS Vol. 10, No. 2, October 2020 : 167 - 178 
pengendalian ON/OFF untuk $L E D$ sebagai analogi lampu taman yang dilakukan untuk 3 (tiga) posisi, yaitu posisi $L E D \# 1, L E D \# 2$, dan $L E D \# 3$.

\section{HASIL DAN PEMBAHASAN}

\subsection{Bentuk Fisis Prototipe Perangkat Berbasis Web}

Bentuk fisis prototipe perangkat untuk pemantauan dan pengendalian berbasis web yang dapat diintegrasikan ke smarthome system dilakukan melalui (i) analisis kebutuhan perangkat keras dan prinsip operasi prototype perangkat, (ii) konsepsi pengintegrasian perangkat keras, dan (iii) perakitan terintegrasi dan pemanfaatan jaringan.

\subsubsection{Analisis kebutuhan perangkat keras dan prinsip operasi prototipe perangkat}

Cakupan pada analisis kebutuhan perangkat keras dan prinsip operasi prototipe perangkat. Tahapan analisis kebutuhan dilakukan terhadap beberapa perangkat keras sebagai bahan penelitian utama dan bahan lain untuk penunjang penelitian. Sensor jarak jenis ultrasonik atau lebih dikenal dengan sensor ultrasonik, digunakan untuk pendeteksi dan pengukur secara kualitatif terhadap ketinggian air pada tangki air. Sensor ultrasonik tipe HY-SRF05 merupakan pengembangan dari tipe sebelumnya, yaitu HC-SR04. Tipe HY-SRF05 juga dengan akurasi lebih tepat dibandingkan dengan tipe HC-SR04. Penggunaan NodeMCU dari Lolin versi 3 dengan antarmuka $U S B$ yang lebih cepat dibandingkan dengan versi sebelumnya dan berdimensi lebih besar, karena keberadaan 2 pin cadangan untuk daya dengan konektor USB, juga terdapat jalur ground (GND) tambahan.

Prinsip operasi dijelaskan melalui arah urutan di dalam prototipe perangkat untuk pemantauan dan pengendalian berbasis web. Diagram skematis prinsip operasi prototipe perangkat, seperti ditunjukkan pada Gambar 3.

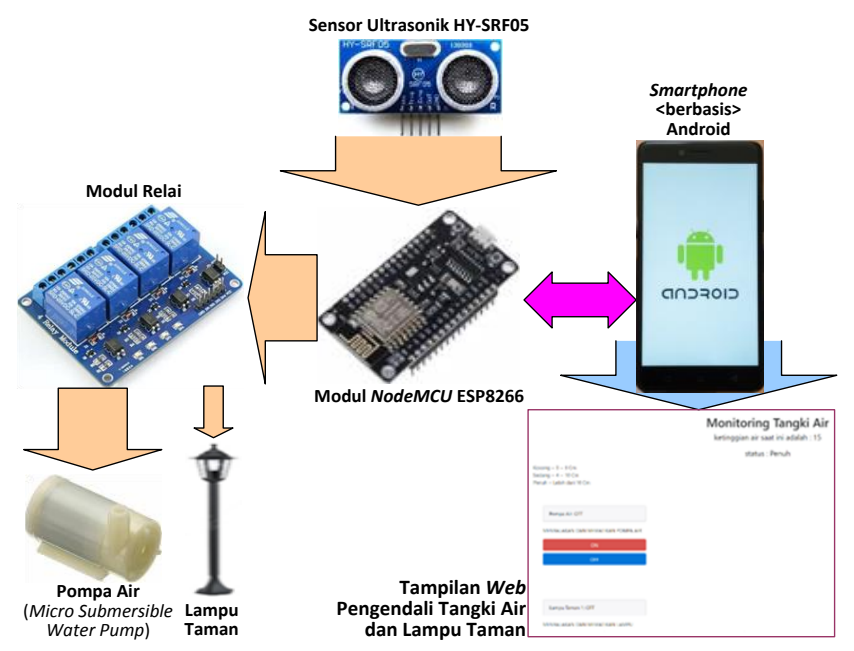

Gambar 3. Diagram skematis prinsip operasi prototipe perangkat

Berdasarkan Gambar 3 dapat dijelaskan, bahwa prinsip operasi sistem dimulai dari sensor ultrasonik HY-SRF05 dengan fungsi pendeteksian terhadap ketinggian permukaan air pada tangki air. Pendeteksian terhadap ketinggian air pada tangki air dihasilkan fenomena fisis yang diubah ke besaran listrik oleh sensor dan sinyal listrik tersebut dikirim ke NodeMCU. Data ketinggian permukaan air pada tangki air ditampilkan pada aplikasi berbasis web di smartphone (berbasis) Android. Kondisi ketinggian permukaan air pada tangki dideteksi pada posisi rendah, maka sistem web kirim perintah ke relai untuk pengoperasian motor listrik arus searah penggerak pompa (mikro) air dan ketika kondisi ketinggian permukaan air pada tangki dideteksi pada posisi tinggi, maka motor listrik arus searah dinonaktifkan. Aplikasi web pada smartphone berbasis Android dapat juga digunakan untuk pengaktifan lampu taman atau penonaktifannya. 


\subsubsection{Konsepsi pengintegrasian perangkat keras}

Tahapan pengintegrasian didasarkan kepada konsepsi pengurutan setiap peranti elektronika penyusun prototipe perangkat untuk pemantauan dan pengendalian posisi ketinggian air pada tangki air dan pengoperasian 3 (tiga) buah $L E D$ sebagai analogi lampu taman, sehingga sejumlah modul elektronika, yaitu sensor ultrasonik HY-SRF05, NodeMCU, dan relai untuk pengoperasian atau penonoperasian motor listrik arus searah untuk pompa air dan pengaktifan atau penonaktifan $L E D$ sebagai analogi lampu taman. Sensor ultrasonik HY-SRF05 dengan 5 pin, yaitu VCC, Trig, Echo, OUT, dan GND. Pin Trig digunakan untuk pembangkitan sinyal ultrasonik dan pin Echo digunakan untuk pendeteksian sinyal pantulan ultrasonik. Sensor ini merupakan pendeteksi kondisi ketinggian permukaan air pada tangki air sekaligus sebagai pengubah (transduser) parameter fisis menjadi parameter elektris yang terhubung ke jalur masukan pada modul NodeMCU. Motor listrik arus searah penggerak pompa mikro dapat beroperasi untuk penghisapan air dari sumber dan pengaliran air ke tangki air. Modul relai berupa 4 channel atau 2 modul masing-masing 2 channel dengan empat peruntukan, yaitu submodul 1 untuk pengoperasian motor listrik arus searah, submodul 2 untuk penyalaan $L E D \# 1$, submodul 3 untuk penyalaan $L E D \# 2$, dan submodul 4 untuk penyalaan $L E D \# 3$.

\subsubsection{Perakitan terintegrasi dan pemanfaatan jaringan}

Diagram skematis integrasi prototipe perangkat dan pemanfaatan jaringan, seperti ditunjukkan pada Gambar 4.

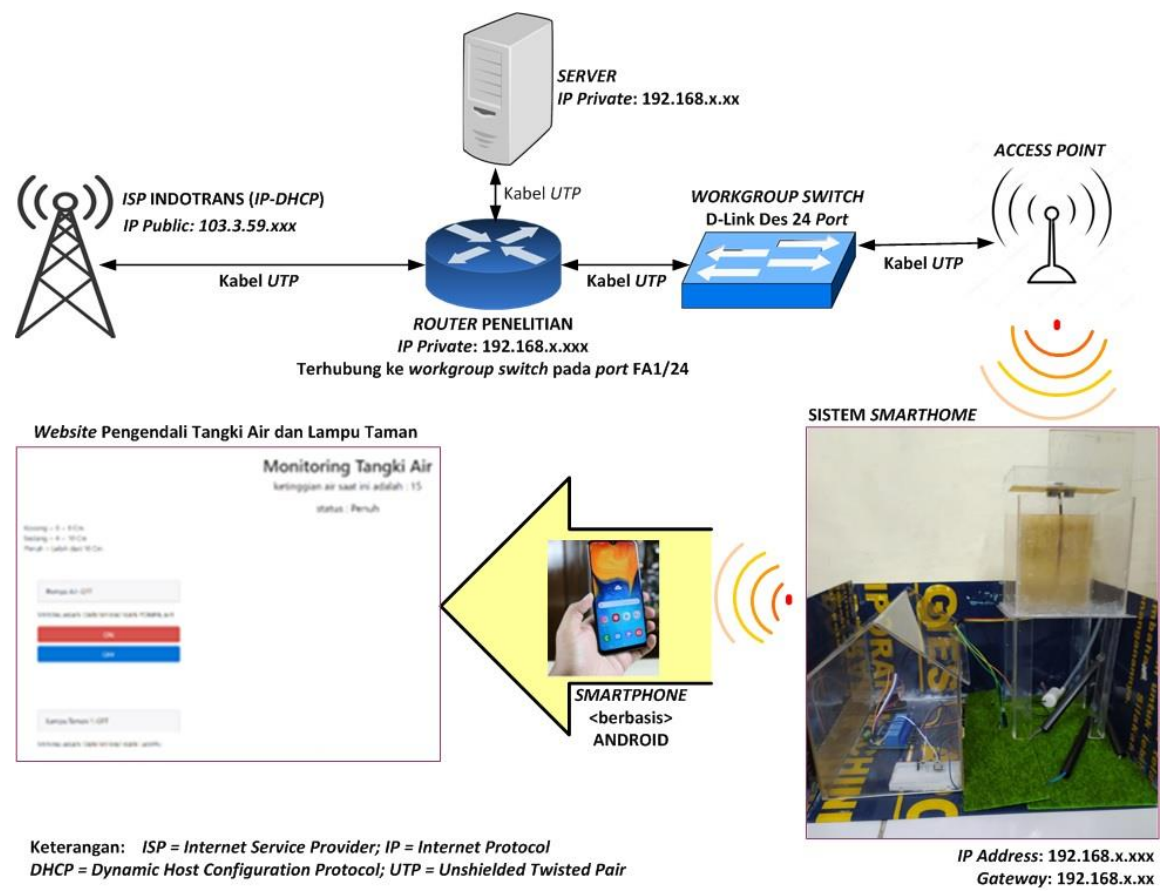

Gambar 4 Diagram skematis integrasi prototipe perangkat dan pemanfaatan jaringan

Berdasarkan Gambar 4 dapat dijelaskan, bahwa perakitan terintegrasi dan pemanfaatan jaringan berupa penyambungan modul NodeMCU ke Access Point. Keterhubungan Access Point ke workgroup switch (switch pada CISCO) digunakan dengan kabel UTP, selanjutnya workgroup switch dihubungkan ke MikroTik Router (diberi nama Router Penelitian), juga dengan kabel UTP. Penghubungan Router Penelitian ke server dan ISP Indotrans, digunakan kabel UTP. Penyediaan IP Public 103.3.59.xxx diperuntukan ke Router Penelitian saat terhubung ke ISP Indotrans yang dikonversikan oleh Router Penelitian, sehingga diperoleh IP Private 192.168.x.xxx, dilanjutkan dengan keterhubungan server ke Router Penelitian dengan IP Private 192.168.x.xx. Workgroup switch terhubung ke Router Penelitian dengan IP Address 192.168.x.xxx/24, sedangkan sistem smarthome terhubung ke Access Point dengan IP Address

IJEIS Vol. 10, No. 2, October 2020 : 167 - 178 
192.168.x.xxx/24.dan Gateway 192.168.x.xx, agar dapat dilakukan pemantauan dan pengendalian terhadap sistem smarthome berbasis web melalui smartphone berbasis Android.

\subsection{Pemrograman Prototipe Perangkat untuk Pemantauan dan Pengendalian}

Perolehan hasil dari tahapan pengintegrasian dan implementasi pemanfaatan jaringan, maka dilakukan langkah-langkah lanjutan berupa pemrograman. Pemrograman dibuat untuk (i) mikrokontroler berbasis bahasa Arduino IDE, (ii) web berupa pemantauan dan pengendalian pada komputer personal berbasis Arduino IDE, (iii) web berupa pemantauan dan pengendalian pada smartphone berbasis aplikasi sublime text versi 3, dan (iv) penentuan server mandiri berbasis aplikasi XAMPP versi 3.2.4.

\subsubsection{Pemrograman mikrokontroler NodeMCU}

Tahapan pemrograman untuk mikrokontroler berbasis bahasa Arduino IDE, melalui penentuan algoritma dan penulisan sintaks yang dilanjutkan dengan proses compiling dan uploading terhadap source code dari PC ke dalam mikrokontroler NodeMCU.

\#1) Algortima dan sintaks

Penentuan algoritma yang dilanjutkan dengan penulisan sintaks berbasis bahasa pemrograman $\mathrm{C}$, agar diperoleh sejumlah source code sebagai inti pengoperasian mikrokontroler NodeMCU. Perolehan algoritma dapat berbentuk diagram alir. Perolehan sebuah prototipe dengan source code berbasis bahasa pemrograman $\mathrm{C}$ merupakan bentuk minimalis sebuah sistem tertanam (embedded system). Diagram alir untuk pemrograman mikrokontroler, seperti ditunjukkan pada Gambar 5.

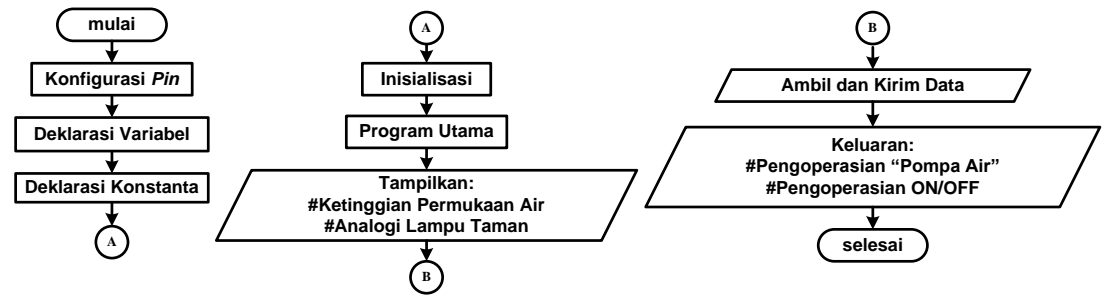

Gambar 5 Diagram alir untuk pemrograman mikrokontroler

Berdasarkan Gambar 5 dapat dijelaskan, bahwa pemrograman mikrokontroler diperlukan pentahapan konfigurasi pin, deklarasi variabel dan konstanta, inisialisasi, program utama, ambil dan kirim data, dan keluaran.

Permintaan pengalamatan Internet Protocol (IP) secara Dynamic Host Control Protocol (DHCP) pada MikroTik RouterBoard sekaligus untuk penetapan NodeMCU pada MikroTik RouterBoard dengan kondisi modul NodeMCU beroperasi dengan baik, maka IP tertampilkan pada monitor Arduino IDE. Untuk kondisi dimana terdapat masalah, maka tertampil error pada monitor Arduino IDE. Diagram alir untuk pengaktifan NodeMCU, seperti ditunjukkan pada Gambar 6.
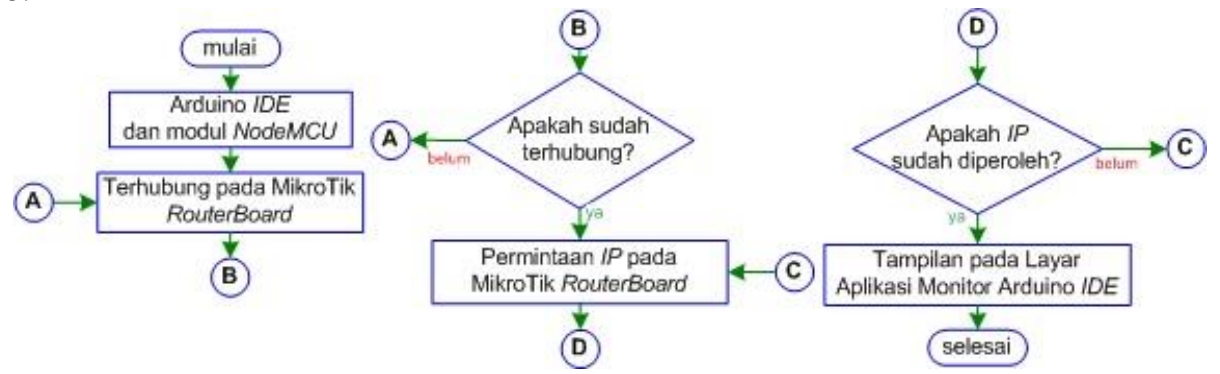

Gambar 6 Diagram alir untuk pengaktifan NodeMCU

Berdasarkan Gambar 6, disusun struktur sintaks sintaks untuk pengaktifan NodeMCU. Setelah penyelesaian susunan sintaks, diperlukan compiling pada Arduino IDE yang telah berisi script pengaktifan. Tampilan hasil pengaktifan NodeMCU pada layar Arduino IDE, seperti ditunjukkan pada Gambar 7. 


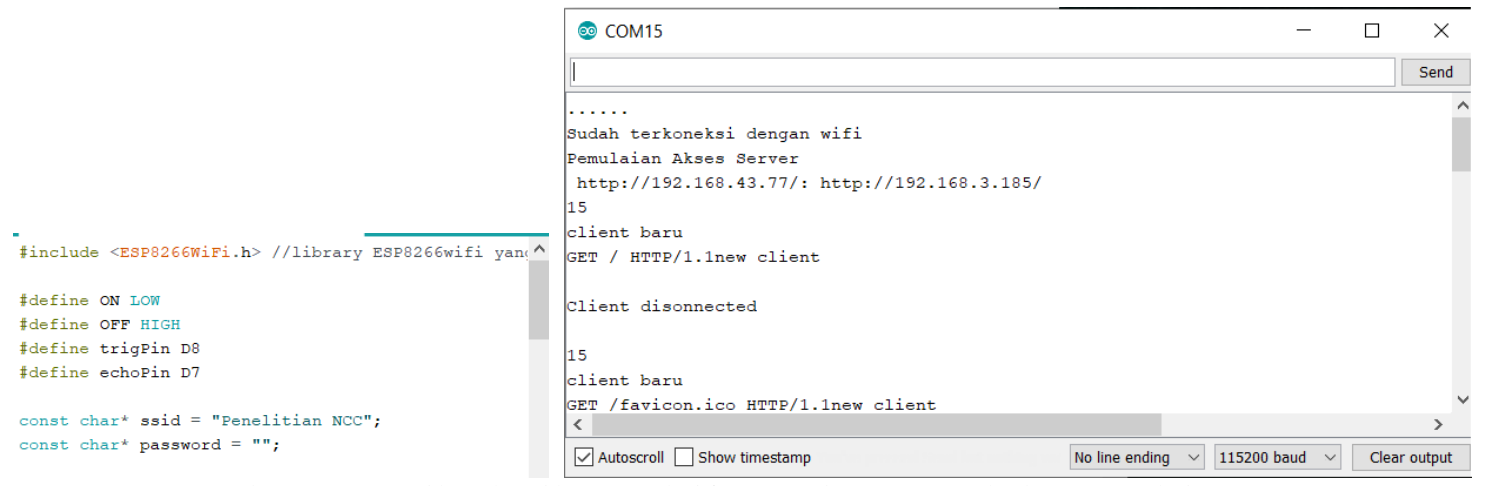

Gambar 7 Tampilan hasil pengaktifan NodeMCU pada layar Arduino IDE

Berdasarkan Gambar 7 ditunjukkan, bahwa setelah pengaktifan modul NodeMCU pada Arduino $I D E$, maka dapat dilakukan proses lanjutan berupa pembuatan source code tersebut, agar NodeMCU tersebut dapat berfungsi untuk pemantau ketinggian permukaan air di tangki air dan pengendalian $L E D$ sebagai analogi lampu taman.

\#2) Compiling dan uploading terhadap source code ke dalam mikrokontroler NodeMCU

Tahapan compiling dan uploading terhadap source code ke dalam mikrokontroler NodeMCU merupakan tahapan setelah penentuan algoritma dan penulisan sintaks untuk perolehan sejumlah source code. Proses compiling dan uploading terhadap source code ke dalam mikrokontroler NodeMCU dari $P C$, dilakukan dengan bantuan kabel USB. Tampilan proses compiling dan uploading terhadap source code dari $P C$ ke mikrokontroler NodeMCU, seperti ditunjukkan pada Gambar 8.

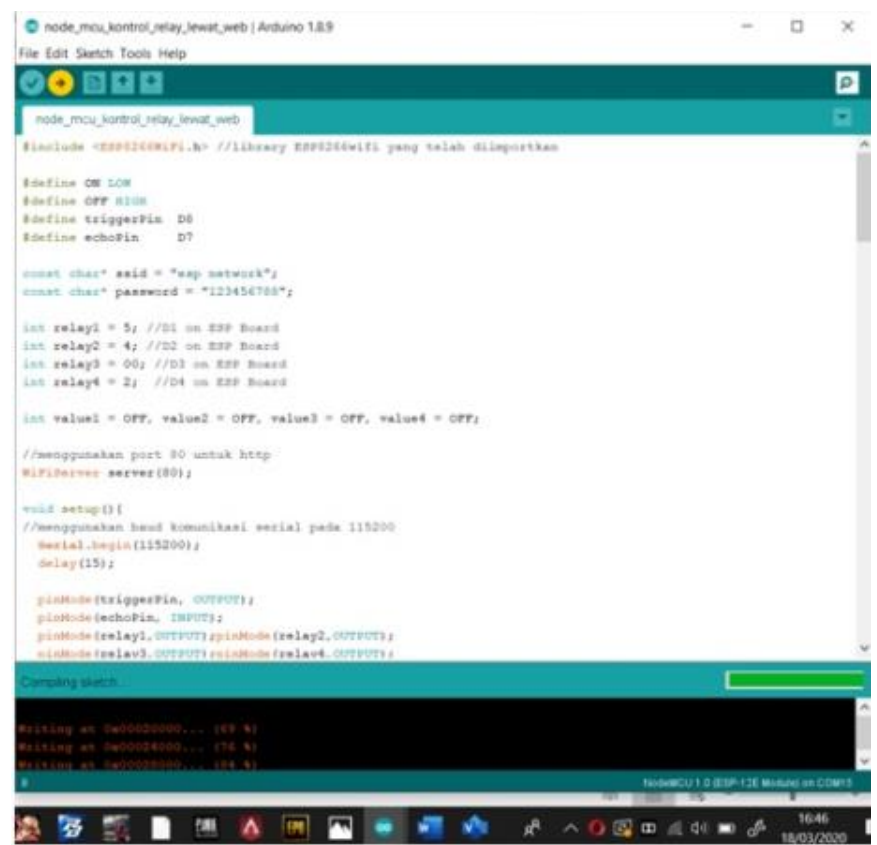

Gambar 8 Tampilan proses compiling dan uploading terhadap source code dari PC ke mikrokontroler NodeMCU

\subsubsection{Aplikasi web untuk pemantauan dan pengendalian pada komputer personal}

Web untuk pemantauan dan pengendalian (web monitoring) digunakan pada komputer personal untuk pembuatan aplikasi sebagai sistem pemantauan dan pengendalian. Pembuatan web monitoring dibuat pada aplikasi Arduino IDE bersama dengan program pembuatan untuk web monitoring di smarthome. Setelah pembuatan web monitoring pada aplikasi Arduino IDE, maka dilakukan pemasukan alamat IP pada aplikasi browser Google Chrome yang sudah diperoleh dari MikroTik RouterBoard. Tampilan proses masukan alamat IP pada aplikasi browser Google Chrome pada komputer personal, seperti ditunjukkan pada Gambar 9.

IJEIS Vol. 10, No. 2, October 2020 : 167 - 178 


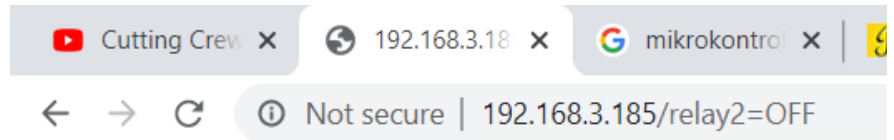

Gambar 9 Tampilan proses masukan alamat IP pada aplikasi browser Google Crome pada komputer personal

Berdasarkan Gambar 9 ditunjukkan, bahwa proses pemasukan alamat IP pada aplikasi browser Google Chrome pada komputer personal telah berhasil. Perolehan hasil selanjutnya berupa pembukaan tampilan halaman web pada aplikasi Google Chrome. Tampilan web pengontrol tangki air dan lampu taman berupa 3 (tiga) kriteria monitoring dengan pencantuman kosong = 0-3 cm, sedang $=4-10 \mathrm{~cm}$, penuh $=$ lebih dari $10 \mathrm{~cm}$, dan berupa 4 kolom kontrol .

\subsection{Kinerja Prototipe Perangkat dan Implementasi Jaringan Saat Terintegrasi ke Smarthome System}

Pengamatan dengan pemberian kondisi untuk proses pemantauan ketinggian permukaan air pada tangki air dan pengendalian terhadap analogi lampu taman dilakukan untuk perolehan hasil kondisi tangki air pada kriteria "kosong" atau "sedang" atau "penuh" dan pemberian perintah untuk pengendalian analogi lampu taman \#1, \#2, dan \#3.

\subsubsection{Pemantauan ketinggian permukaan air pada tangki air}

Pemantauan ketinggian permukaan air pada tangki air dikelompokkan kepada 3 (tiga) kondisi, yaitu kriteria "kosong", "sedang", dan "penuh". Hasil pemantauan ketinggian permukaan air pada tangki air, seperti ditunjukkan pada Tabel 1.

Tabel 1 Hasil pemantauan dan pengendalian terhadap tangki air

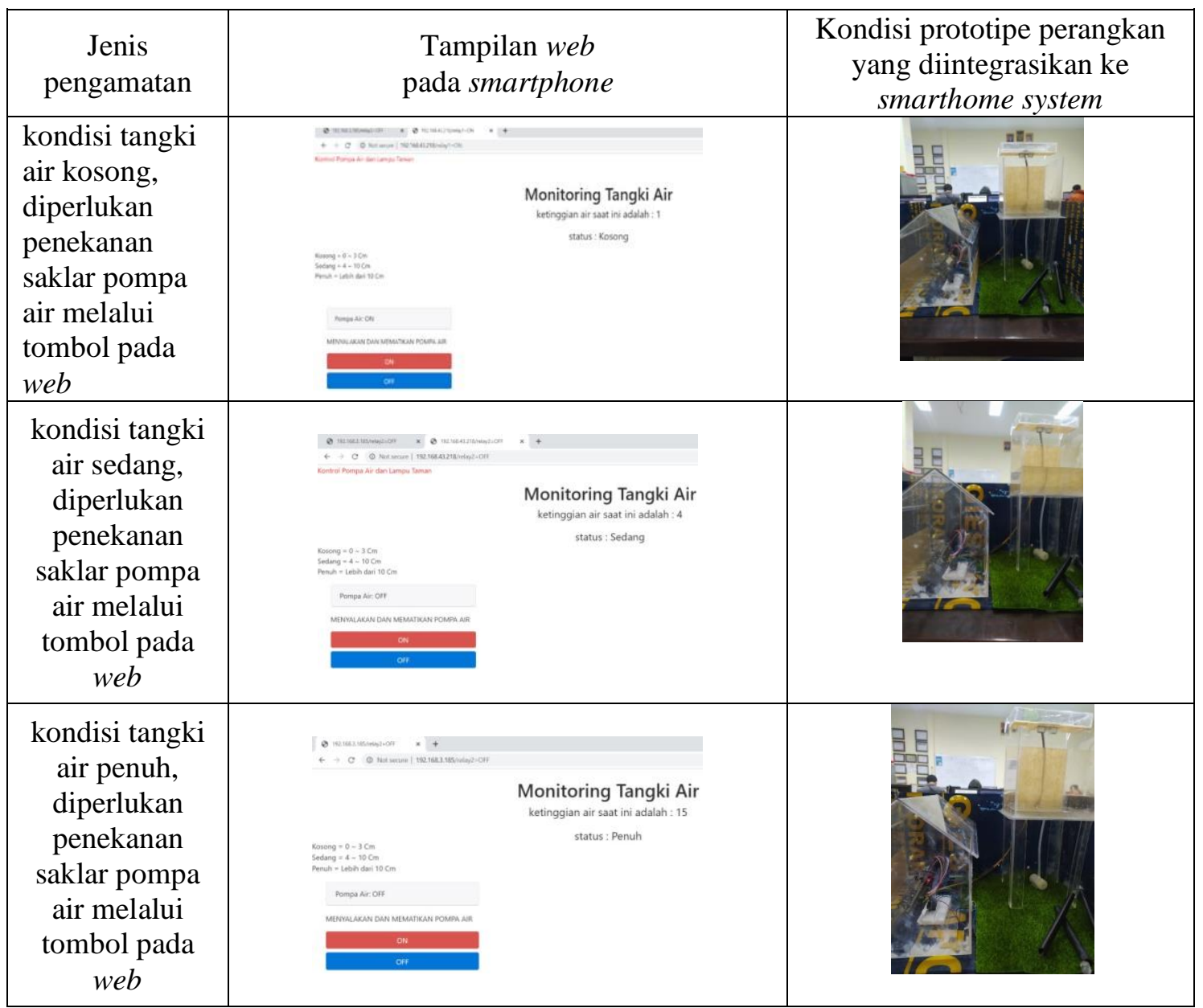


Berdasarkan Tabel 1 ditunjukkan, bahwa terdapat keterangan untuk ketinggian air pada tangki 0-3 cm dengan kriteria "kosong", ketinggian air pada tangki 4-10 cm dengan kriteria "sedang", dan untuk ketinggian air pada tangki lebih dari $10 \mathrm{~cm}$ dengan kriteria "penuh".

\subsubsection{Pengendalian ON/OFF untuk LED sebagai analogi lampu taman}

Pengendalian secara ON/OFF terhadap $L E D$ sebagai analogi lampu taman, dilakukan untuk 3 (tiga) posisi, yaitu posisi \#1, \#2, dan \#3. Hasil pengendalian terhadap LED \#1, LED \#2, dan $L E D \# 3$, seperti ditunjukkan pada Tabel 2.

Tabel 2 Hasil pengendalian terhadap $L E D \# 1, L E D$ \#2, dan $L E D$ \#3

\begin{tabular}{|c|c|c|}
\hline $\begin{array}{c}\text { Jenis } \\
\text { pengamatan }\end{array}$ & $\begin{array}{l}\text { Tampilan web } \\
\text { pada smartphone }\end{array}$ & $\begin{array}{l}\text { Kondisi prototipe perangkan } \\
\text { yang diintegrasikan ke } \\
\text { smarthome system }\end{array}$ \\
\hline $\begin{array}{l}\text { pengendalian } \\
L E D \# 1 \text { ON, } \\
\text { kondisi tombol } \\
\text { saklar } L E D \# 2 \\
\text { dan \#3 pada } \\
\text { web OFF }\end{array}$ & 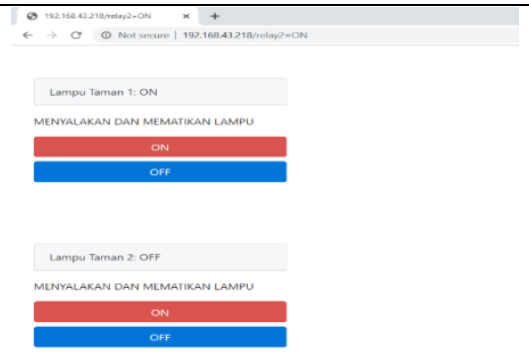 & In \\
\hline $\begin{array}{l}\text { pengendalian } \\
L E D \# 2 \text { ON } \\
\text { dan } L E D \# 1 \\
\text { tetap ON, } \\
\text { kondisi tombol } \\
\text { saklar } L E D \# 3 \\
\text { pada web OFF }\end{array}$ & 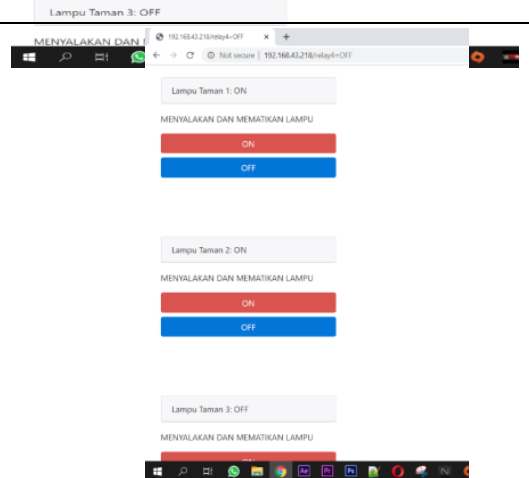 & \\
\hline $\begin{array}{l}\text { pengendalian } \\
L E D \# 3 \text { ON, } \\
L E D \# 1 \text { dan } \\
L E D \# 2 \text { tetap } \\
\text { ON, kondisi } \\
\text { tombol saklar } \\
L E D \# 1, L E D \\
\# 2 \text {, dan } L E D \\
\# 3 \text { pada web } \\
\text { ON }\end{array}$ & 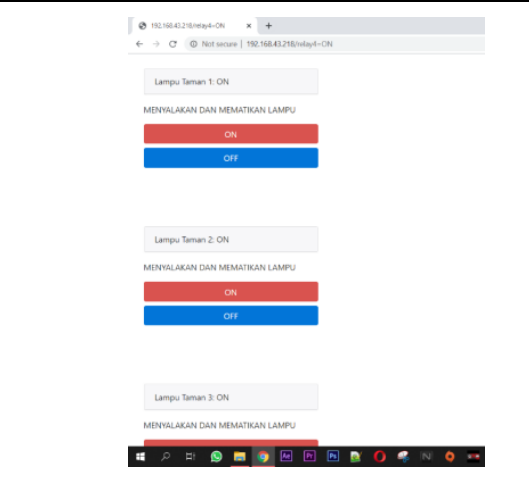 & 2 \\
\hline
\end{tabular}

Berdasarkan Tabel 2 ditunjukkan, bahwa (i) $L E D$ \#1 menyala sesaat setelah tombol saklar-\#1 ditekan ke ON, kondisi $L E D \# 2$ dan \#3 padam dan keadaan saklar untuk $L E D \# 2$ dan \#3 pada kondisi OFF, maka status pada web ditampilkan informasi saklar pada $L E D \# 1$ ON, LED \#2 dan \#3 kondisi OFF; (ii) LED \#2 menyala sesaat setelah tombol saklar-\#2 ditekan ke ON, kondisi LED \#1 menyala, sedangkan kondisi $L E D$ \#3 padam dan keadaan saklar untuk $L E D$ \#3 pada kondisi OFF, maka status pada web ditampilkan informasi saklar pada $L E D \# 1$ dan $L E D \# 2$

IJEIS Vol. 10, No. 2, October 2020 : 167 - 178 
kondisi ON dan \#3 kondisi OFF; dan (iii) LED \#3 menyala sesaat setelah tombol saklar-\#3 ditekan ke ON, sedangkan kondisi $L E D$ \#1 dan $L E D$ \#2 tetap menyala, maka status pada web ditampilkan informasi saklar pada $L E D \# 1, L E D \# 2$, dan $L E D \# 3$ kondisi ON.

\section{KESIMPULAN}

Berpedoman kepada hasil dan pembahasan, maka dapat ditarik kesimpulan sesuai sasaran penelitian. Bentuk fisis prototipe perangkat berbasis web dilakukan perakitan terintegrasi dan pemanfaatan jaringan dengan urutan, yaitu (i) penyambungan modul NodeMCU ke Access Point, (ii) ke workgroup switch (switch pada CISCO) digunakan dengan kabel UTP, (iii) dihubungkan ke MikroTik Router (diberi nama Router Penelitian), juga dengan kabel UTP, (iv) ke server dan ISP Indotrans, digunakan kabel UTP, (v) penyediaan IP Public 103.3.59.xxx yang dikonversikan oleh Router Penelitian, sehingga diperoleh IP Private 192.168.x.xxx, dilanjutkan dengan keterhubungan server ke Router Penelitian dengan IP Private 192.168.x.xx, dan (vi) IP Address 192.168.x.xxx/24, sedangkan sistem smarthome terhubung ke Access Point dengan IP Address 192.168.x.xxx/24 dan Gateway 192.168.x.xx, agar dapat dilakukan pemantauan dan pengendalian terhadap sistem smarthome berbasis web melalui smartphone berbasis Android. Tahapan pemrograman untuk mikrokontroler berbasis bahasa Arduino IDE, melalui penentuan algoritma dan penulisan sintaks yang dilanjutkan dengan proses compiling dan uploading terhadap source code dari $P C$ ke dalam mikrokontroler NodeMCU. Tahapan compiling dan uploading terhadap source code ke dalam mikrokontroler NodeMCU merupakan tahapan setelah penentuan algoritma dan penulisan sintaks untuk perolehan sejumlah source code. Proses compiling dan uploading terhadap source code ke dalam mikrokontroler NodeMCU dari $P C$, dilakukan dengan bantuan kabel USB. Web untuk pemantauan dan pengendalian (web monitoring) digunakan pada komputer personal untuk pembuatan aplikasi sebagai sistem pemantauan dan pengendalian. Pengamatan dengan pemberian kondisi untuk proses pemantauan ketinggian permukaan air pada tangki air dan pengendalian terhadap analogi lampu taman. Perolehan hasil kondisi tangki air dengan kriteria kosong $(0-3 \mathrm{~cm})$ atau sedang (4$10 \mathrm{~cm}$ ) atau penuh (lebih dari $10 \mathrm{~cm}$ ) dan pemberian perintah untuk pengendalian analogi lampu taman \#1, \#2, dan \#3.

\section{DAFTAR PUSTAKA}

[1] Wagino and Arafat, "Monitoring dan Pengisian Air Tandon Otomatis Berbasis Arduino," Technologia Jurnal Ilmiah, vol. 9, no. 3, pp. 192-196, Juli-September 2018 [Online]. Available: https://ojs.uniska-bjm.ac.id/index.php/JIT/article/view/1414/1185. [Accessed: 30-Jan-2020].

[2] C. Navaneethan and S. Meenatchi , "Water Level Monitoring using Blynk Application in IoT," International Journal of Recent Technology and Engineering (IJRTE), vol. 8, no. 4, pp. 1676-1679, November 2019 [Online]. Available: https://www.ijrte.org/wpcontent/uploads/papers/v8i4/C5358098319.pdf. [Accessed: 20-Jan-2020]

[3] I. Gunawan and T. Akbar, "Prototipe Penerapan Internet of Things (Iot) pada Monitoring Level Air Tandon Menggunakan NodeMCU ESP8266 dan Blynk," Infotek: Jurnal Informatika dan Teknologi, vol. 3, no. 1, pp. 1-7, Januari 2020 [Online]. Available: http://ejournal.hamzanwadi.ac.id/index.php/infotek/article/download/1789/pdf 20. [Accessed: 17Mar-2020]

[4] A.S. Aviv, A. Wardayanti, E. Budiningsih, A.K. Fimani, and B. Suhardi, "Water Level Control Sistem Otomatis Sederhana pada Tandon Air di Kawasan Perumahan," Performa: Media Ilmiah Teknik Industri, vol. 15, no. 2, pp. 130-136, September 2016 [Online]. Available: https://jurnal.uns.ac.id/performa/article/view/9864/8780. [Accessed: 30-Jan2020] 
[5] W. Widiasih and H. Murnawan, "Rancang Bangun Unit Pengendali Ketinggian Air Dalam Tandon," Jurnal Teknik Industri HEURISTIC, vol. 13, no. 2, pp.124-135, Oktober 2016 [Online]. Available: sby.ac.id/index.php/HEURISTIC/article/download/880/79. [Accessed: 21-Nov-2019]

[6] A. Goeritno, F. Hendrian, and Ritzkal, "Pengendalian Lampu Pijar pada Analogi Instalasi Listrik Fase-Tiga melalui Smartphone Berbasis Android Berbantuan Jaringan Wi-Fi," Jurnal Ilmiah SETRUM, vol. 8, no. 2, pp. 274-286, Desember 2019 [Online]. Available: http://jurnal.untirta.ac.id/index.php/jis/article/download/6977/pdf_62. [Accessed: 30-Jan2020]

[7] E. Dainow, Understanding Computers, Smartphones and the Internet, $1^{\text {st }}$ ed. Toronto, CA: CreateSpace, 2018.

[8] A. Goeritno, B.A. Prakoso, and B.A. Prakosa, "Kinerja Sistem Kontrol Berbasis Mikrokontroler Untuk Pemantauan Sejumlah Parameter Fisis pada Analogi Smart Green House," Prosiding Simposium Nasional Rekayasa Aplikasi Perancangan dan Industri (RAPI XV) 2016, Fakultas Teknik, Universitas Muhammadiyah Surakarta, 7th December 2016, pp. 70-76 [Online]. Available: https://publikasiilmiah.ums.ac.id/bitstream/handle/11617/8172/B49_Arief\%20Goeritno.pdf ?sequence=1\&isAll owed=y. [Accessed: 30-Jan-2020]

[9] M.T. Sholehati and A. Goeritno, "Sistem Minimum Berbasis Mikrokontroler ATmega2560 sebagai Sistem Pengaman pada Analogi Lemari Penyimpanan Brankas," Jurnal Rekayasa Elektrika, vol. 14, no. 3, pp. 158-166, Desember 2018 [Online]. Available: http://www.jurnal.unsyiah.ac.id/JRE/article/download/11649/pdf. [Accessed: 30-Jan-2020]

[10] A. Goeritno, Ritzkal, and A. Johan, "Kinerja Prototipe Sistem Elektronis Berbasis Mikrokontroler Arduino Uno R3 Untuk Pemantauan Analogi Instalasi Listrik," Jurnal Ilmiah SETRUM, vol. 5, no. 2, pp. 94-99, Desember 2016 [Online]. Available: http://jurnal.untirta.ac.id/index.php/jis/article/download/971/772. [Accessed: 20-Jan-2020]

[11] R. Saputra, P.F. Ariyani, and N. Juliasari, "Sistem Monitoring Stok Tangki Air Memanfaatkan Sensor Ultrasonik dan Mikrokontroler Arduino Mega pada Depot Air Minum," Jurnal BIT: Budi Luhur Information Technology, vol. 15, no. 1, pp. 1-8, 2018. https://journal.budiluhur.ac.id/index.php/bit/article/download/678/559. [Accessed: 20-Jan2020]

[12] M. Banzi and M. Shiloh, Make: Getting Started with Arduino: the Open Source Electronics Prototyping Platform, 3rd Edition. Sebastopol, CA: Maker Media, 2015.

[13] F. Masykur and F. Prasetiyowati, "Aplikasi Rumah Pintar (Smart Home) Pengendali Peralatan Elektronik Rumah Tangga Berbasis Web," Jurnal Teknologi Informasi dan Ilmu Komputer, vol. 3, no. 1, pp. 51-58, Maret 2016 [Online]. Available: http://jtiik.ub.ac.id/index.php/jtiik/article/download/156/pdf. [Accessed: 20-Jan-2020]

[14] Y-L. Hsu, P-H. Chou, H-C. Chang, S-L. Lin, S-C. Yang, H-Y. Su, C-C. Chang, Y-S. Cheng, and Y-C. Kuo, "Design and Implementation of a Smart Home System Using Multisensor Data Fusion Technology," Sensors, vol. 17, no. 07, pp. 1-21, 2017 [Online]. Available: https://res.mdpi.com/d attachment/sensors/sensors-1701631/article_deploy/sensors-17-01631.pdf. [Accessed: 20-Jan-2020] 